\title{
Editorial: Celebrating 50 Years of Occupational Therapy in Iran
}

\author{
Samantha Shann ${ }^{1^{*}}$ (D)
}

1. President, World Federation of Occupational Therapists (WFOT), London, United Kingdom.

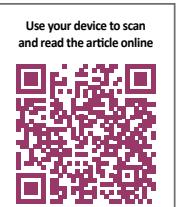

Cftatton: Shann S. Celebrating 50 Years of Occupational Therapy in Iran. Iranian Rehabilitation Journal. 2022; 20(Special Issue):1-2. http://dx.doi.org/10.32598/irj.20.SpecialIssue.1650.1

doi) http://dx.doi.org/10.32598/irj.20.Speciallssue.1650.1

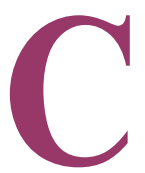

elebrating milestones is important. It provides a means of reflection and opportunity to give thanks to those that have come before us and as such fifty years of occupational therapy in Iran is a very worthy milestone to acknowledge. As we pause to celebrate this achievement, we take a moment to reflect on the journey to date, recognizing the accomplishments of many.

The history of occupational therapy can be traced back through the centuries and its emergence as a profession has been shaped by socially constructed expectations and values, which are often influenced by the dominance of professional theories and models originated in the privileged English-speaking global north [1]. Therefore, the emergence of occupational therapy in Iran 50 years ago is of international significance as we recognize the development of a culturally relevant profession, which continually adapts and grows to meet the needs of the people of Iran.

With the primary goal of occupational therapy being to enable people to participate in the activities of everyday life [2], we can see that occupational therapy philosophy and purpose fit closely with Iranian culture, where being productive has always been important. The Persian proverb "the wise man who does not put his knowledge into practice is like a bee that gives no honey' compliments Reilly's [3] believe that "Man, through the use of his hands, as they are energized by mind and will, can influence the state of his own health".

However, the growth of occupational therapy in Iran has not been without its challenges. Whilst the 1960s saw the Iranian government in conjunction with the World Health Organization prioritize the expansion of rehabilitation programs and formally recognize the need for occupational therapy services and education programs. The following years of revolution and war, unfortunately, saw universities close, and many academics and practitioners leave the country. Then, as seen in other countries, the armed conflict brought with it an increased need and demand for occupational therapy with the number of people with disabilities significantly increasing. The establishment of the Iranian Occupational Therapy Association (IROTA) in 1994 enabled the profession to come together and provide a national voice and focal point to advocate for occupational therapy education, practice standards, and an increase in the number of service providers [4]. Full membership of IROTA to the World Federation of Occupational Therapists (WFOT) in 2006 was an accumulation of this work and to date, IROTA continues to be a valued and essential member of WFOT shaping the professional agenda on an international scale.

Since WFOT started collating data in 2006 until the latest figures, there has been a $100 \%$ increase in the

\footnotetext{
* Corresponding Author: 
number of occupational therapists who are members of IROTA and a 50\% increase in the number of occupational therapists practicing in Iran, from 2,000 in 2006 to 3,000 in 2020 [5]. This positive increase is testimony to the hard work of many, yet also indicates the quality of occupational therapy education in Iran. The range of $\mathrm{BSc}, \mathrm{MSc}$, and doctoral level education has significantly affected the quality and scope of research being carried out and fits with Watson's [6] belief that "traditional epistemologies must be challenged, and assumptions, values, and beliefs adjusted in order to match cultural needs".

As we move forward, it is essential to consider the impact of the last 18 months and the significant contributions that occupational therapy has made to the COVID-19 rehabilitation process in Iran and globally [7]. The world's understanding of the need for participation in meaningful occupations has probably never been greater and as with previous societal events, the pandemic has brought opportunities as well as challenges. The World Health Organization has repeatedly highlighted access to rehabilitation services as essential in embracing universal health coverage and achieving the UN Sustainable Development Goals 2030 agenda. It is therefore important that any national rehabilitation strategy for Iran addresses both COVID-specific rehabilitation needs plus the needs of those who require rehabilitation for other reasons $[8,9]$. Within this, there is an opportunity for Iranian occupational therapists to embrace new ways of working, to ensure occupational therapy services meet clients' and societal needs and thereby promote occupational therapy within a wide range of different social and cultural contexts.

Therefore, as we celebrate the achievements of the last 50 years, we can look forward to the next 50 years knowing that occupational therapy education, practice, and research in Iran has never been stronger. Congratulations on your accomplishments, thank you for your contributions to the development of occupational therapy nationally and internationally, and your wishes for occupational therapy in Iran to achieve further milestones driven and shaped by your beautiful culture. The profession is wellpositioned to build on the achievements of the past whilst capturing and demonstrating the unique contribution of occupational therapy to influence policymakers for the future benefit of the health and well-being of the people of Iran.

\section{Ethical Considerations}

\section{Compliance with ethical guidelines}

There were no ethical considerations to be considered in this research.

\section{Funding}

This research did not receive any grant from funding agencies in the public, commercial, or non-profit sectors.

\section{Conflict of interest}

The author declared no conflict of interest.

\section{References}

[1] Hammell KW. Building globally relevant occupational therapy from the strength of our diversity. World Federation of Occupational Therapists Bulletin. 2019 ;75(1):13-26. [DOI:10.1 080/14473828.2018.1529480

[2] Yazdani F. The dynamic nature of attributing meaning and value to occupation in Iran. Journal of Occupational Science. 2012; 19(4):371-5. [DOI:10.1080/14427591.2012.701180]

[3] Reilly M. Occupational therapy can be one of the great ideas of 20th century medicine. The American Journal of Occupational Therapy. 1962; 16:1-9. [PMID]

[4] Rassafiani M, Sahaf R, Yazdani F. Occupational therapy in Iran: Past, present and future. Annals of International Occupational Therapy. 2018; 1(1):49-56. [DOI:10.3928/2476122220180212-04

[5] WFOT. Occupational Therapy Human Resources Project 2020: Alphabetical. Published: May 2020. https://wfot.org/ resources/occupational-therapy-human-resources-project2020-alphabetical

[6] Watson RM. Being before doing: The cultural identity (essence) of occupational therapy. Australian Occupational Therapy Journal. 2006; 53(3): 151-8. [DOI:10.1111/j.14401630.2006.00598.x]

[7] Hoel V, Zweck CV, Ledgerd R, World Federation of Occupational Therapists. The impact of Covid-19 for occupational therapy: Findings and recommendations of a global survey. World Federation of Occupational Therapists Bulletin. 2021; 1-8 https://caot.ca/document/7610/WFOT_COVIDRrecommendationsGlobalSurvey_Jan2021.pdf

[8] De Biase S, Cook L, Skelton DA, Witham M, Ten Hove R The COVID-19 rehabilitation pandemic. Age and Ageing. 2020; 49(5):696-700. [PMID] [PMCID]

[9] Gutenbrunner C, Stokes EK, Dreinhöfer K, Monsbakken J, Clarke S, Côté P, et al. Why Rehabilitation must have priority during and after the COVID-19-pandemic: A position statement of the Global Rehabilitation Alliance. Journal of Rehabilitation Medicine. 2020; 52(7):jrm00081. [PMID] 